dần theo thứ tự trước, bên, sau, từ trên xuống dưới sự khác biệt có ý nghĩa thống kê với $p$ < 0,05 (Biểu đồ 2.2). Hơn nữa điểm siêu âm phổi vùng sau đóng góp nhiều nhất trong tổng điểm siêu âm của cả phổi giống với nghiên cứu của Luigi Pisani $(2019)^{6}$. Điều này được có thể giải thích do ngoài tác dụng của trọng lực, vùng phổi này còn chịu tác động của lực bên ngoài như áp lực ổ bụng, dịch màng phổi, áp lực ổ bụng và kích thước tim.

Điểm siêu âm phổi tổng và ba vùng trước, bên, sau ở ba phân nhóm mức độ nhẹ, vừa, nặng theo phân loại Berlin khác biệt không có ý nghĩa thống kê với $p>0,05$ (Biểu đồ 2.3) khác với nghiên cứu của Luigi Pisani (2019) khi điểm siêu âm phổi vùng sau tăng dần theo mức độ nă̆ng của ARDS.

3. Hạn chế của nghiên cứu. Nghiên cứu của chúng tôi còn một số hạn chế nhất định. Kết quả siêu âm phổi có được phụ thuộc chủ quan của người nghiên cứu, chúng tôi cũng chưa đưa đánh giá được độ lặp lại (Repeatablity/Testretest reliability), sự nhất quán của người chẩn đoán cũng như giữa những người chẩn đoán (intraobserver và interobserver ). Cõ̃ mẫu của chúng tôi nhỏ, cần có những nghiên bổ sung để đưa đưa ra những kết luận có thể đại diện tốt cho quần thể nghiên cứu.

\section{KẾT LUẬN}

Hình ảnh siêu âm phân bố không đều giữa các vùng phổi với hình ảnh đông đặc, B2 tập trung chủ yễu tại vùng sau, dưới của phổi

\section{TÀI LIỆ THAM KHẢO}

1. Gattinoni $L$, Pesenti A. The concept of "baby lung." Intensive Care Med. 2005;31(6):776-84.

2. Mongodi S, Pozzi M, Orlando A et al. Lung ultrasound for daily monitoring of ARDS patients on extracorporeal membrane oxygenation: preliminary experience. ntensive Care Med. 2018;44(1):123-124.

3. Bouhemad $B$, Brisson $H$, Le-Guen $M$ et al. Bedside ultrasound assessment of positive endexpiratory pressure-induced lung recruitment. Am J Respir Crit Care Med. 2011;183(3):341-7.

4. Ferguson N. D, Fan E, Camporota L. The Berlin definition of ARDS: an expanded rationale, justification, and supplementary material. Intensive Care Med. 2012;38(10):1573-82.

5. A. Sanjan, S. Vimal Krishnan, Siju V. Abraham, Babu Urumese Palatty. Utility of Point-of-Care Lung Ultrasound for Initial Assessment of Acute Respiratory Distress Syndrome Patients in the Emergency Department. J Emerg Trauma Shock. 2019;12(4):248-253.

6. Luigi P et al. The diagnostic accuracy for ARDS of global versus regional lung ultrasound scores - a post hoc analysis of an observational study in invasively ventilated ICU patient. Intensive Care Medicine Experimental. 2019;7(Suppl 1):44.

\title{
ĐĂC ĐIỂM TRÂM CẢM TRÊN THANG ĐIỂM PHQ-9 Ở BỆNH NHÂN UNG THƯ ĐƯờNG TIÊU HÓA TẠI BỆNH VIỆN K
}

\section{TÓM TẮT}

Mục tiêu: Đánh giá đăc điểm trâm cảm trên thang điểm PHQ-9 ở bệnh nhân ung thư đường tiêu hóa tại bệnh viện K. Đối tượng: 124 bệnh nhân đã chẩn đoán xác định ung thư đường tiêu hóa và điều trị tại bệnh viện $K$ từ tháng $8 / 2020$ đến tháng 10/2020. Phướng pháp: Nghiên cứu mô tả cắt ngang. Kết quả: Tỷ lệ nam/nữ là 2,6/1, tuổi trung bình là $57,9 \pm 9,65$. Đa số có trình độ dưới lớp 10 $(57,3 \%)$ và độc thân/góa $(93,5 \%)$. Trầm cảm thường gặp nhất ở ung thư đại trực tràng $(52,4 \%)$, tiếp theo là ung thư thực quản $(27,4 \%)$ và ít nhất ở ung thư da dày $(20,2 \%)$, đa số bệnh nhân ở giai đoạn III-IV $(64,5 \%)$. Có mối liên quan có ý nghĩa thống kê giữa

${ }^{1}$ Bệnh viện $K$

Chịu trách nhiệm chính: Đỗ Tuyết Mai

Email: bsdotuyetmai@gmail.com

Ngày nhận bài: 5.3.2021

Ngày phản biên khoa học: 28.4.2021

Ngày duyệt bài: 6.5.2021

\section{Đỗ Tuyết Mai ${ }^{1}$, Nguyễn Tiến Quang ${ }^{1}$}

trâm cảm với ung thư thực quản ( $\mathrm{p}<0,001$; $\mathrm{OR}=$ $1,009,95 \% \mathrm{CI}=0,359-2,838)$ và ung thu đại trực tràng $(p<0,05 ; O R=0,901,95 \% C I=0,358-2,273)$. Có mối liên quan có ý nghĩa thống kê giữa trâm cảm với giai đoan IV với $\mathrm{p}<0,05(\mathrm{OR}=0,196 ; 95 \% \mathrm{CI}=$ 0,058-0,660). Theo thang điểm PHQ-9 có 45,2\% bệnh nhân ung thư đường tiêu hóa có biểu hiên trâm cảm và $17,8 \%$ có trầm cảm mức độ trung bình trở lên cân được can thiệp. Kết luận: Trầm cảm thường gặp ở người bệnh ung thư đường tiêu hoa. Có mối liên quan có ý nghĩa thống kê giữa trầm cảm với ung thư thực quản, đại trực tràng và giai đoạn muộn.

Tư khóa: Trâm cảm, ung thư đường tiêu hóa, đặc điểm, PHQ-9.

\section{SUMMARY}

THE CHARACTERISTICS OF DEPRESSION WITH THE PHQ-9 IN GASTROINTESTINAL

CANCER PATIENTS AT K HOSPITAL

Objective: To assess the characteristic of depression with $\mathrm{PHQ}-9$ in patients with gastrointestinal cancers at K hospital. Subject: 124 patients were 
diagnosed gastrointestinal cancer and treated at $\mathrm{K}$ hospital from August 2020 to October 2020. Methods: A cross-sectional descriptive study. Result: The male/female ratio was 2.6. The average age was $57,9 \pm 9,65$. The majority of patients had educational level below $10^{\text {th }}$ grade $(57.3 \%)$ and was single/widowed (93.5\%). Depression was most common in colorectal cancer $(52.4 \%)$, followed by esophageal cancer (27.4\%), and least in stomach cancer $(20.2 \%)$, mostly in stage III-IV (64.5\%). There was a statistically significant association between depression and esophageal cancer $(\mathrm{p}<0.001$; OR $=$ $1.009,95 \% \mathrm{CI}=0.359-2.838)$ and colorectal cancer $(p<0.05 ;$ OR $=0.901,95 \%$ CI $=0.358-2,273)$. There was no statistically significant association between depression and cancer stage. According to the PHQ-9 scale, $45.2 \%$ of patients with gastrointestinal cancer had depression and $17.8 \%$ with moderate or severe depression needed intervention. Conclusion: Depression is common in patients with gastrointestinal cancer. There is a statistically significant association between depression and esophageal and colorectal cancers.

Keywords: Depression, gastrointestinal cancer, characteristics, PHQ-9.

\section{I. ĐẶT VẤN ĐỀ}

Ung thư là căn bệnh nguy hiểm có thể đe dọa tính mạng con người, trong đó thường gặp nhất là các loại ung thư đường tiêu hóa như ung thư đại trực tràng, dạ dày và thực quản. Theo thống kể của GLOBOCAN năm 2020, riêng ung thư đại trực tràng đứng thứ 3 vể tỷ lệ mắc mới (hơn 1,9 triệu người) và xếp thứ 2 về tỷ lệ tử vong (935.173 ca) trong tổng số các loại ung thư [1].

Nhiêu nghiên cứu đã chứng minh rằng trầm cảm là một trong những rối loạn tâm thần thường gặp nhất ở người bệnh ung thư với tỷ lệ 20-35\% [2]. Bệnh nhân ung thư đường tiêu hóa có nhiều hạn chế về chức năng sống có nguy cơ trầm cảm tới $30 \%$ [3]. Trầm cảm có thể làm tăng các triệu chứng cơ thể, giảm tuân thủ điều trị ung thư và tăng tỷ lệ tự sát. Nghiên cứu đã chứng minh rằng triệu chứng trầm cảm làm giảm chất lượng cuộc sống của bệnh nhân ung thư và tăng tỷ lệ tử vong từ 25-39\% [4], [5].

Bộ câu hỏi PHQ-9 (Patient Health Questionnaire - 9 items) là một công cụ sàng lọc trầm cảm đơn giản và hiệu quả, đã được chuẩn hóa và sử dụng rộng rãi tại Việt Nam [6]. Tuy nhiên tại Việt Nam chưa có nghiên cứu nào đánh giá đặc điểm trầm cảm bằng thang điểm $\mathrm{PHQ}-9$ ở người bệnh ung thư đường tiêu hóa, do đó chúng tôi thực hiện đề tài "Đặc điểm trầm cảm trên thang điểm PHQ-9 ở bệnh nhân ung thư đường tiêu hóa tại Bệnh viện $\mathrm{K}^{\prime \prime}$ nhằm làm rõ vấn đề này.

\section{II. ĐỐI TƯợNG VÀ PHƯƠNG PHÁP NGHIÊN CỨU}

2.1. Đối tượng, địa điểm và thời gian: 124 bênh nhân được chẩn đoán và điều trị ung thư đường tiêu hóa tại Bệnh viện $\mathrm{K}$ từ 08/2020 đến 10/2020 với:

- Tiêu chuấn lưa chon: Bệnh nhân từ 18 tuổi trở lên được chẩn đoán và điêu trị ung thư đường tiêu hóa tại Bệnh viện $\mathrm{K}$ cơ sở Tân Triêu, có khả năng đọc hiểu nghiển cứu. Trong nghiên cứu này chúng tôi tập trung vào nhóm bệnh nhân ung thư ống tiểu hóa bao gồm ung thư thực quản, dạ dày, ruột non, đại tràng, trực tràng và ống hậu môn.

- Tiêu chuẩn loại trừ: Các bênh nhân từ chối tham gia nghiên cứu, bệnh nhân có sa sút trí tuệ, chậm phát triển tâm thần.

\subsection{Phương pháp nghiên cứu:}

- Thiết kế nghiên cứu: Nghiên cứu mô tả cắt ngang.

- Các bước thu thập số liệu: Bệnh nhân đã được chẩn đoán và điều trị ung thư đường tiêu hóa được giải thích và mời tham gia nghiên cứu. Những bệnh nhân đồng ý sẽ thực hiện phiếu phỏng vấn gồm thông tin về tuổi, giới, trình độ văn hóa, tình trạng hôn nhân, vị trí ung thư và giai đoạn bệnh, sau đó thực hiện bộ câu hỏi PHQ-9.

2.3. Xử lý số liệu: Số liệu được nhập và xử lý bằng phần mềm SPSS 20.0, sử dụng thống kê mô tả (\%, trung bình) và xác định mối tương quan bằng kiểm định Chi square với $\mathrm{p}<0,05$ được coi là có ý nghĩa thống kê.

\section{KẾT QUẢ NGHIÊN CỨU}

3.1. Đặc điểm chung của nhóm đối tượng nghiên cứu

Bảng 3.1. Đặc điểm chung của nhóm đối tượng nghiên cứu

\begin{tabular}{|c|c|c|c|}
\hline Đặc & điếm & $\mathbf{n}$ & $\%$ \\
\hline & Nam & 90 & 72,6 \\
\hline Giởi tinh & Nữ & 34 & 27,4 \\
\hline Tuối (Mc & $\operatorname{ean} \pm S D)$ & 57,9 & 9,65 \\
\hline Trình độ văn & Dưới lớp 10 & 71 & 57,3 \\
\hline hóa & Từ lớp 10 trở lên & 53 & 42,7 \\
\hline Tình trạng hôn & Kết hôn & 8 & 6,5 \\
\hline nhân & Độc thân/Góa & 116 & 93,5 \\
\hline & Thực quản & 34 & 27,4 \\
\hline Vị trí ung thư & Dạ dày & 25 & 20,2 \\
\hline & Đại, trực tràng & 65 & 52,4 \\
\hline Cỉi đton hônh & I-II & 44 & 35,5 \\
\hline Glal doạn bẹnn & III-IV & 80 & 64,5 \\
\hline $\begin{array}{l}\text { Thời gian từ khi } \\
\text { chẩn đoán } \\
\text { (tháng) }\end{array}$ & Mean \pm SD & $8,6=$ & 3,27 \\
\hline 10 & & 124 & 100 \\
\hline
\end{tabular}


Nhận xét: Trong 124 bênh nhân nghiên cứu có $72,6 \%$ bệnh nhân nam và $27,4 \%$ bệnh nhân nữ. Tỷ lệ nam/nữ xấp xỉ 2,6. Tuối trung bình của đối tượng nghiên cứu là 57,9 tuổi. Có $57,3 \%$ bênh nhân có trình đô dưới lớp 10 và đa số độc thân hoặc góa (chiếm 93,5\%). Loại ung thư thường gặp nhất là đại trực tràng (chiếm $52,4 \%)$, tiếp theo là ung thư thực quản $(27,4 \%)$ và ít nhất là dạ dày $(20,2 \%)$. Đa số bệnh nhân ở giai đoạn III-IV (chiếm 64,5\%), thời gian từ khi chẩn đoán trung bình 8,6 tháng.

\subsection{Mối liên quan giữa trâm cảm và vị trí ung thư}

Bảng 3.2. Môi liên quan giữa tràm cảm và vị trí ung thư'

\begin{tabular}{|c|c|c|c|c|c|c|}
\hline \multirow{2}{*}{ Vị trí ung thư } & \multicolumn{2}{|c|}{$\mathbf{P H Q}-\mathbf{9}<\mathbf{1 0}$} & \multicolumn{2}{|c|}{ PHQ-9 $\mathbf{1 0}$} & \multirow{2}{*}{$\mathbf{~}$} & \multirow{2}{*}{ OR (95\%CI) } \\
\cline { 2 - 5 } & $\mathbf{n}$ & $\mathbf{\%}$ & $\mathbf{n}$ & $\mathbf{\%}$ & & \\
\hline Thực quản & 28 & 82,4 & 6 & 17,6 & 0,000 & $1,009(0,359-2,838)$ \\
\hline Dạ dày & 21 & 84,0 & 4 & 16,0 & 0,065 & $1,167(0,357-3,816)$ \\
\hline Đại, trực tràng & 53 & 81,5 & 12 & 18,5 & 0,048 & $0,901(0,358-2,273)$ \\
\hline
\end{tabular}

Nhận xét: Nghiên cứu nhận thấy tỷ lệ trầm cảm gặp nhiều nhất ở ung thư đại trực tràng $(18,5 \%$ bệnh nhân có $P H Q-9 \geq 10)$, tiếp theo là ung thư thực quản $(17,6 \%$ có $P H Q-9 \geq 10)$, thấp nhất ở bệnh nhân dạ dày $(16 \%$ có $\mathrm{PHQ}-9 \geq 10)$. Có mối liên quan có ý nghĩa thống kê giữa trầm cảm với ung thư thực quản với $\mathrm{p}<0,001(\mathrm{OR}=1,009,95 \% \mathrm{CI}=0,359-2,838)$ và ung thư đại trực tràng với $\mathrm{p}<0,05(\mathrm{OR}=0,901,95 \% \mathrm{CI}=0,358-2,273)$.

3.3. Mối liên quan giữa trâm cảm và giai đoạn bệnh ung thư

Bảng 3.3. Mối liên quan giữa trầm cảm và giai đoạn bệnh ung thư

\begin{tabular}{|c|c|c|c|c|c|c|}
\hline \multirow{2}{*}{$\begin{array}{c}\text { Giai đoạn bệnh ung } \\
\text { thư }\end{array}$} & \multicolumn{2}{|c|}{ PHQ-9 $\mathbf{1 0}$} & \multicolumn{2}{|c|}{ PHQ-9 10 } & \multirow{2}{*}{ P } & \multirow{2}{*}{ OR (95\%CI) } \\
\cline { 2 - 5 } & $\mathbf{n}$ & $\mathbf{9}$ & $\mathbf{n}$ & $\mathbf{9}$ & & \\
\hline I & 13 & 100,0 & 0 & 0,0 & 0,077 & $1,247(1,137-1,368)$ \\
\hline II & 26 & 83,9 & 5 & 16,1 & 0,786 & $1,163(0,390-3,467)$ \\
\hline III & 56 & 83,6 & 11 & 16,4 & 0,676 & $1,217(0,484-3,062)$ \\
\hline IV & 7 & 53,8 & 6 & 46,2 & 0,005 & $0,196(0,058-0,660)$ \\
\hline
\end{tabular}

Nhận xét: Nghiên cứu nhận thấy tỷ lệ trầm cảm cao nhất ở giai đoạn IV (46,2\% bệnh nhân có PHQ-9 $\geq 10$ ), tỷ lệ trầm cảm tương đương ở nhóm giai đoạn II và III (khoảng $16 \%$ có PHQ-9 $\geq 10$ ), không có bệnh nhân nào ở giai đoạn I có biểu hiện trầm cảm trên thang điểm PHQ-9. Có mối liên quan có ý nghĩa thống kê giữa trầm cảm với giai đoạn IV với $\mathrm{p}<0,05$ ( $\mathrm{OR}=0,196$; $95 \% \mathrm{CI}=0,058-0,660)$.

3.4. Đặc điểm mức độ trâm cảm theo thang PHQ-9

Bảng 3.4. Đặc điểm mức độ trâm cảm theo thang PHQ-9

\begin{tabular}{|c|c|c|}
\hline Theo thang PHQ-9 & $\mathbf{n}$ & $\mathbf{\%}$ \\
\hline Không trầm cảm (<5 điểm) & 68 & 54,8 \\
\hline Trầm cảm nhẹ (5-9 điếm) & 34 & 27,4 \\
\hline $\begin{array}{c}\text { Trầm cảm trung bình (10-14 } \\
\text { điểm) }\end{array}$ & 13 & 10,5 \\
\hline $\begin{array}{c}\text { Trầm cảm nằng }(\geq 15 \\
\text { điểm) }\end{array}$ & 9 & 7,3 \\
\hline Tổng & 124 & 100 \\
\hline
\end{tabular}

Nhận xét: Trên thang điểm PHQ-9, nghiên cứu nhận thây có $45,2 \%$ bệnh nhân ung thư đường tiêu hóa có biểu hiện trầm cảm, trong đó chủ yếu là trầm cảm nhe (chiếm 27,4\%) và trầm cảm mức trung bình $(10,5 \%)$, có $7,3 \%$ bệnh nhân có trầm cảm nặng.

\section{BÀN LUÂN}

4.1. Đặc điểm chung của nhóm đôii tượng nghiên cứu. Trong 124 bệnh nhân nghiên cứu có $72,6 \%$ bệnh nhân nam và $27,4 \%$ bệnh nhân nữ. Tỷ lệ nam/nữ xấp xỉ 2,6. Tuổi trung bình của đối tượng nghiên cứu là 57,9 tuổi. Có $57,3 \%$ bênh nhân có trình đô dưới lớp 10 và đa số độc thân hoặc góa (chiếm 93,5\%). Loại ung thư thường gặp nhất là đại trực tràng (chiếm 52,4\%), tiếp theo là ung thư thực quản $(27,4 \%)$ và ít nhất là dạ dày $(20,2 \%)$. Đa sô bệnh nhân ở giai đoạn III-IV (chiếm 64,5\%), thời gian từ khi chẩn đoán trung bình 8,6 tháng. Kết quả này tương đồng với nghiên cứu của Jungwa nhận thấy đa số bênh nhân ung thư đường tiêu hóa là nam giới $(76,7 \%)$, trình độ dưới THPT $(65 \%)$, tỷ lệ ung thư đại trực tràng chiếm đa số trong các loại ung thư đường tiêu hóa $(33,3 \%)$ [3].

4.2. Mối liên quan giữa trâm cảm và vị trí ung thư. Nghiên cứu của chúng tôi nhận thấy tỷ lệ trầm cảm gặp nhiều nhất ở ung thư đại trực tràng $(18,5 \%$ bệnh nhân có $\mathrm{PHQ}-9 \geq$ $10)$, tiếp theo là ung thư thực quản $(17,6 \%$ có 
PHQ-9 $\geq 10$ ), thấp nhất ở bệnh nhân dạ dày $(16 \%$ có PHQ-9 $\geq 10)$. Có mối liên quan có ý nghĩa thống kê giữa trâm cảm với ung thư thực quản với $\mathrm{p}<0,001(\mathrm{OR}=1,009,95 \% \mathrm{CI}=$ $0,359-2,838)$ và ung thư đại trực tràng với $p<$ $0,05(\mathrm{OR}=0,901,95 \% \mathrm{CI}=0,358-2,273)$. Kết quả này phù hợp với nghiên cứu của Jungwa nhận thây có mối liên quan có ý nghĩa thống kê giữa vị trí ung thư và trầm cảm, đặc biệt là ung thư dạ dày $(\mathrm{OR}=5,39,95 \% \mathrm{CI}=0,37-78,23)$ và đại trực tràng $(\mathrm{OR}=3,63,95 \% \mathrm{CI}=0,25-52,81)$ [3]. Nghiên cứu của chúng tôi ghi nhận tỷ lệ trầm cảm ở bệnh nhân ung thư thực quản cao hơn so với các nghiên cứu khác, có thể lý giải do tỷ lệ ung thư thực quản còn cao ở Việt Nam, đa số phát hiện ở giai đoạn muộn và ảnh hưởng nặng nề hơn tới tâm lý và chất lượng sống của bệnh nhân. Nghiên cứu của Hartung cũng cho thây tỷ lệ trầm cảm trong ung thư thực quản/dạ dày là $27 \%$ và ung thư đại trực tràng là $24 \%$, liên quan có ý nghĩa thống kê với $p<0,001$ [7].

4.3. Mối liên quan giữa trâm cảm và giai đoạn bệnh ung thư. Nghiên cứu nhận thấy tỷ lệ trầm cảm cao nhất ở giai đoạn IV $(46,2 \%$ bệnh nhân có $\mathrm{PHQ}-9 \geq 10$ ), tỳ lệ trầm cảm tương đương ở nhóm giai đoạn II và III (khoảng $16 \%$ có $\mathrm{PHQ}-9 \geq 10$ ), không có bệnh nhân nào ở giai đoạn I có biểu hiện trầm cảm trên thang điểm PHQ-9. Có mối liên quan có ý nghĩa thống kê giữa trầm cảm với giai đoạn IV với $p<0,05$ $(\mathrm{OR}=0,196 ; 95 \% \mathrm{CI}=0,058-0,660)$. Kết quả này phù hợp với nghiên cứu của Jungwa [3], có thể lý giải do bệnh nhân ung thư đường tiêu hóa ở giai đoạn muộn có nhiều triệu chứng cơ thể hơn, bị hạn chế nhiêu hơn về các hoạt động sống, từ đó dẫn tới nhiều căng thẳng và nguy cơ trầm cảm cao hơn ở giai đoạn sớm.

4.4. Đặc điểm trâm cảm theo thang PHQ-9. Trên thang điểm PHQ-9, nghiên cứu nhận thây có $45,2 \%$ bệnh nhân ung thư đường tiêu hóa có biểu hiện trầm cảm, trong đó chủ yếu là trầm cảm nhẹ (chiếm $27,4 \%$ ) và trầm cảm mức trung bình $(10,5 \%)$, có 7,3\% bệnh nhân có trầm cảm nặng. Kết quả này phù hợp với nghiên cứu của Hartung sử dụng thang PHQ9 sàng lọc trầm cảm ở bệnh nhân ung thư nhận thấy có $60 \%$ bệnh nhân có điểm PHQ-9 $\geq 5$ và $24 \%$ có điểm PHQ-9 $\geq 10$, đặc biệt tỷ lệ trầm cảm nặng ở nhóm ung thư tiêu hóa gần $10 \%$ [7]. Tỷ lệ trầm cảm trong nghiên cứu này cao hơn nghiển cứu của Jungwa với $25,8 \%$ có điểm PHQ-9 $\geq 10$ [3], có thể lý giải do nghiên cứu của chúng tôi có tỷ lệ cao bệnh nhân độc thân/góa
$(93,5 \%)$ và ung thư giai đoạn muộn III-IV $(64,5 \%)$, dẫn tới gánh nặng tâm lý cao hơn và hỗ trợ tinh thần ít hơn, làm tăng tỷ lệ trầm cảm chung. Nhìn chung tỷ lệ trầm cảm ở bệnh nhân ung thư đường tiêu hóa có thể dao động từ 25$60 \%$ với tỷ lệ đáng kể trầm cảm vừa và nặng cần được can thiệp tâm lý và/hoặc thuốc. Các nhà lâm sàng cần lưu ý nhu cầu hố trợ về tâm lý xã hội của bệnh nhân ung thư đặc biệt ung thư đường tiêu hóa để kịp thời hỗ trợ, chăm sóc toàn diện và điều trị hiệu quả bệnh ung thư.

\section{KẾT LUÂN}

Nghiên cứu 124 bệnh nhân ung thư đường tiêu hóa tại Bệnh viện $K$ từ tháng 8/2020 đến 10/2020 chúng tôi có nhận xét sau: Đối tượng nghiên cứu chủ yếu là nam giới, tuổi trung bình là 58. Vị trí ung thư tiêu hóa thường gặp tương ứng với tỷ lệ có trầm cảm lần lượt là đại trực tràng, thực quản và thấp nhất là dạ dày, đa số ở giai đoạn muộn với tỷ lệ trầm cảm cao hơn. Có mối liên quan có ý nghĩa thống kê giữa trầm cảm với ung thư thực quản, ung thư đại trực tràng và giai đoan muộn. Theo thang PHQ-9 có hơn 45\% bệnh nhân ung thư tiêu hóa có biểu hiện trầm cảm và $17,8 \%$ cần được điều trị.

\section{TÀI LIÊU THAM KHẢO}

1. International Agency for Research on Cancer W.H.O. (2020). Vietnam fact sheets. Globocan 2020.

2. Jimmie C. Holland, William S. Breitbart, Paul B. Jacobsen, (2018), Psycho-Oncology Hardback - Matthew J. Loscalzo, Ruth McCorkle, Phyllis N. Butow -, Oxford University Press.

3. Chung J., Ju G., Yang J. và cộng sự. (2018). Prevalence of and factors associated with anxiety and depression in Korean patients with newly diagnosed advanced gastrointestinal cancer. Korean J Intern Med, 33(3), 585-594.

4. Lee $Y_{\text {., }}$ Lin $P_{.}-Y_{\text {., }}$ Lin 'M.-C. và cộng sự. (2019). Morbidity and associated factors of depressive disorder in patients with lung cancer. Cancer Manag Res, 11, 7587-7596.

5. Satin J.R., Linden W., và Phillips M.J. (2009). Depression as a predictor of disease progression and mortality in cancer patients: a meta-analysis. Cancer, 115(22), 5349-5361.

6. Hinz A., Mehnert A., Kocalevent R.-D. và cộng sự. (2016). Assessment of depression severity with the PHQ-9 in cancer patients and in the general population. BMC Psychiatry, 16.

7. Hartung T.J., Brähler E., Faller H. và cộng sự. (2017). The risk of being depressed is significantly higher in cancer patients than in the general population: Prevalence and severity of depressive symptoms across major cancer types. Eur J Cancer, 72, 46-53. 